\title{
Investigating the barriers of the green human resource management implementation in oil industry
}

\author{
Marjan Fayyazi ${ }^{\text {** }}$, Saeed Shahbazmoradi ${ }^{\mathrm{b}}$, Zahra Afshar ${ }^{\mathrm{c}}$ and Mohammad Reza Shahbazmoradi
}

${ }^{a}$ Assistant Professor, Human Resource Management Department, University of Tehran, Iran

${ }^{b}$ Director of research and strategic planning of human resources in Oil Industry, Iran

${ }^{c}$ Master of Human Resource Management, Management Department, Tehran university, Tehran, Iran

C H R O N I C LE

Article history:

Received August 18, 2014

Accepted 26 November 2014

Available online

December 72014

Keywords:

Green human resource

management

Green management

Environmental Oil industry

Green

\begin{abstract}
A B S T R A C T
There is a growing need for the integration of environmental management into Human Resource Management (HRM) practices; such effort is known as Green HRM initiatives. The aim of this study is to identify barriers of green human resource management in Iran's oil industry. For this purpose, mixed method has been used. In the article, existing literature was examined and questions were designed and 12 experts of international oil industry were interviewed. The aim of these interviews was to design questionnaire and collects the necessary information. To examine the reliability of the questionnaires, Cronbach alpha coefficient was equal to 0.732 , which validated the reliability of the questionnaire. Finally, the questionnaires were shared among 31 members of oil's experts and HR managers. The results of the study have shown that the lack of comprehensive plan to implement green HRM and ambiguous of green values were in the highest level and they were considered as the most important barriers. Furthermore, staff resistance had the lowest importance.
\end{abstract}

\section{Introduction}

Today, "being green” has become a norm (Margaretha \& Saragih, 2013) and in the management field, there is a growing research literature on Green marketing, Green accounting, Green, Green management and Green human resource management (Renwick et al., 2013). Also, there is a growing need for the integration of environmental management into Human Resource (HR) called Green HR (Dutta, 2012; Margaretha \& Saragih, 2013). However, it is noteworthy that green human resource management is still in its early stages and many studies in this area is theoretical phase (Jabbour, 2013). Companies now realize that they have to develop a powerful social conscience and green sense of responsibility where corporate responsibility is not just a brand building tool to have, but it is an essential factor for business development (Sathyapriya et al., 2013).

Greening is a holistic process aimed at smarter energy usage, low costs, low wastage using sustainable resources or recyclable materials for end results that are products, targets, etc. (Jafri, 2012). In order 
build green organization, the organization and human resources must increase efficiencies in organizational hierarchies, perform more virtualized work or eliminating unnecessary time spent in the office and optimizing the use of company resources, including travel, etc. Also companies are supporting greener options include telecommuting, flexible work schedules (Sathyapriya et al., 2013) and also, to establish and to maintain a green organization we need to hire people who are interested in environmental issues (Renwick et al., 2013). Written environmental policy, specific targets for improving environmental performance, publication of environmental reports, environmental management system, environmental purchasing policy, environmental training and education, fossil fuel use reducing policy and policy of reducing use of unsustainable product indicators are some of the components of green organization (Ramus, 2002).

Organizations with better environmental performance may raise their overall images and attract high potential employees' attention. The rise on environmentalism drives firms to develop their employees' competence to manufacture products that comply with strict environmental regulations (Chen et al., 2012). Increasing reputation, more attractive public image, more efficient business processes, better recruitment, improve product quality, increasing employee productivity, increasing competitive advantage, increasing confidence, increasing loyalty, commitment and motivation of employee are the results of adoption of green human resource management (Renwick et al., 2013). In addition, according to Renwick et al. (2013) "employee motivation to become involved in environmental activities lags behind that of how organizations develop Green abilities and provide employees with opportunities to be involved in green management organizational efforts”. Correa et al. (2013) stated that many firms may use green human recourse management, have benefited from their implementation, their employees have a better morale and green organizations have better financial performance. Any adoption of environmental standards helps firms profit from reducing their negative environmental effect by improving their labor productivity (Delmas \& Pekovic, 2013).

Now, according to these expression and also the importance of this issue in the oil industry, we need to investigate the barriers on green human resources management in the industry, and this article aims to identify barriers of implementing green human resources management in Iran's oil industry.

\section{Literature review}

A Green Workplace is environmentally sensitive, resource efficient and socially responsible (Sathyapriya et al., 2013). In addition, it incorporates a virtual workplace and green buildings. Google is leading the way not only in its environmental practices but also in publicizing their environmental record (Kaur, 2013). In order to reach environmental sustainability goals, most firms can use suitable human resources management (HRM) practices to stimulate their employees (Paille et al, 2013). Green human resources is associated with using every employee's interface to promote sustainable practices and to increase employee awareness and commitments on the issues of sustainability. In other words, Green HR is the implementation of HRM policies to promote the sustainable implementation of resources within business organizations and, more generally, promotes the cause of environmental sustainability (Sathyapriya et al., 2013). However, it should be noted that Green HRM has a unique characteristics and green human resource subsystems are various from traditional HRM subsystems.

Green organizations have emphasized on importance of green recruitment (Hussain, 2013). It can be defined as the organization activity aimed at locating and motivating potential candidates for existing and predicted job openings. Thus, the recruitment process is aimed to influence on the quantity and type of candidates for a specific vacancy. Little is known about the dynamics of inserting environmental issues in an organization recruitment process. In general, when this activity includes the environmental dimension, the environmental performance of the company is implemented as an element to absorb talents (Jabbour, 2011). Recruitment practices can support effective green management by ensuring that new recruits understand an organization's green culture and share its environmental values 
(Jackson \& Seo, 2010). The job descriptions should reflect the sustainability agenda and the company's website and other research tools available for candidate access clearly outline its greening attempt (Mandip, 2012). Olusanya (2013) investigated on embedding environmental sustainability competencies in human capital training and development. He concluded that green organization would require to use learning in association with environment and sustainability as an intrinsic and continuous part of the social responsibility process. In other words, training and development are essential elements in the implementation of green management (Delmas \& Pekovic, 2013). Training and developmental processes are appropriate mechanisms to facilitate corporate sustainability and pro-environmental practices, which in turn can create an opportunity to develop intellectual capital (Olusanya, 2013). Furthermore, among the green HRM practices considered essential for the success of green management at organizations, green training stands out. According to Teixeira et al. (2012), "green training is one of the most important tools to develop human resources and facilitate the transition to a more sustainable society”.

Performance management programs are essential to guarantee the effectiveness of green management work over time because they guide an employee's performance to the environmental performance desired by an organization (Jabbour \& Santos, 2008). In addition, an effective way to successfully implement Green Performance management successfully is to link performance management with green job description (Mandip, 2012). Approaches to measuring green performance include adopting corporate-wide metrics for assessing resource acquisition, usage and waste; implementing information systems to track resource flows; and conducting field audits to provide employees opportunities to identify problems while gaining information and feedback about the green performance of the firm ( Jackson \& Seo, 2008). Using performance management (PM) in green management provides the challenges to measure green performance standards across various units of the firm, and gaining useful data on the environmental performance of managers. Performance management can cover such topics as environmental incidents, usage of environmental responsibilities, and the communication of environmental concerns and policy (Renwick, 2008).

The reward policies are concentrated on attracting, retaining, and motivating the best employees fostering the development of new knowledge, actions, and abilities, which lead to the achievement of organizational goals (Teixeira et al., 2012). Green organizations consider rewards for recycling and waste reduction activities (Renwick, 2008). In general, green organizations are observed to develop reward systems to produce desirable behaviors in green management, and doing so needs effective employment of both incentives and disincentives (Renwick, 2008). The amount of reward depends on a measure of the environmental behavior of the single employee but without significant results in the environmental performance of the company (Hussain, 2013). Reward's systems and incentives helps us improve reflect corporate commitment to the importance of environmental performance (Daily \& Huang, 2001).

\section{Research methodology}

Mixed methods research is a systematic integration of quantitative and qualitative methods in a single study for purposes of obtaining a better picture and deeper understanding of a phenomenon. Mixed methods can be integrated in such a way that qualitative and quantitative methods maintain their original structures and procedures (Johnson et al., 2007). Combined model used in this study is exploratory. Exploratory designs begin with a primary qualitative phase, then the findings are validated or otherwise informed by quantitative results. This approach is usually employed to develop a standardized (quantitative) instrument in a relatively unstudied area. The qualitative phase identifies important factors, while the quantitative phase applies them to a larger and/or more diverse sample (Borrego et al., 2009). The combinational model used in the study is explorative. The steps of article is described in the following. First, literature is examined and questions are designed. In the next step, in order to recognize identifying indictors, some interviews are executed with industry experts. In the 
study, interviews have been executed with 12 experts in an Iranian Oil industry. In the study, an expert is someone who has at least 10 years of job experience in the oil industry and he has enough knowledge about oil industry, he is educated from university in high degree and he focuses on HRM systems. Interviews were content analyzed in the next step and themes and categories have been identified. To examine reliability of this stage, 2 interviews have been coded by another person and similar results were achieved. In the final step, these indicators have put in the format of questionnaire and were distributed among 31 members of HR managers and top oil's experts. The questionnaire had six axes that include cultural factors, technological, structural factors, management, staff and resources. Alpha Cronbach's coefficient was used to examine the reliability of the questionnaire. The amount of coefficient is equal to 0.732 , which is higher than 0.7 and represents the reliability of the questionnaire.

\section{Data analysis}

As it is mentioned, for the study, in the first step, interviews with oil HR experts was executed. Then the results of these interviews were content analyzed, a questionnaire was designed and it was distributed among 31 oil's top experts and HR managers. Demographic of these individuals is expressed in Fig. 1 as follows,

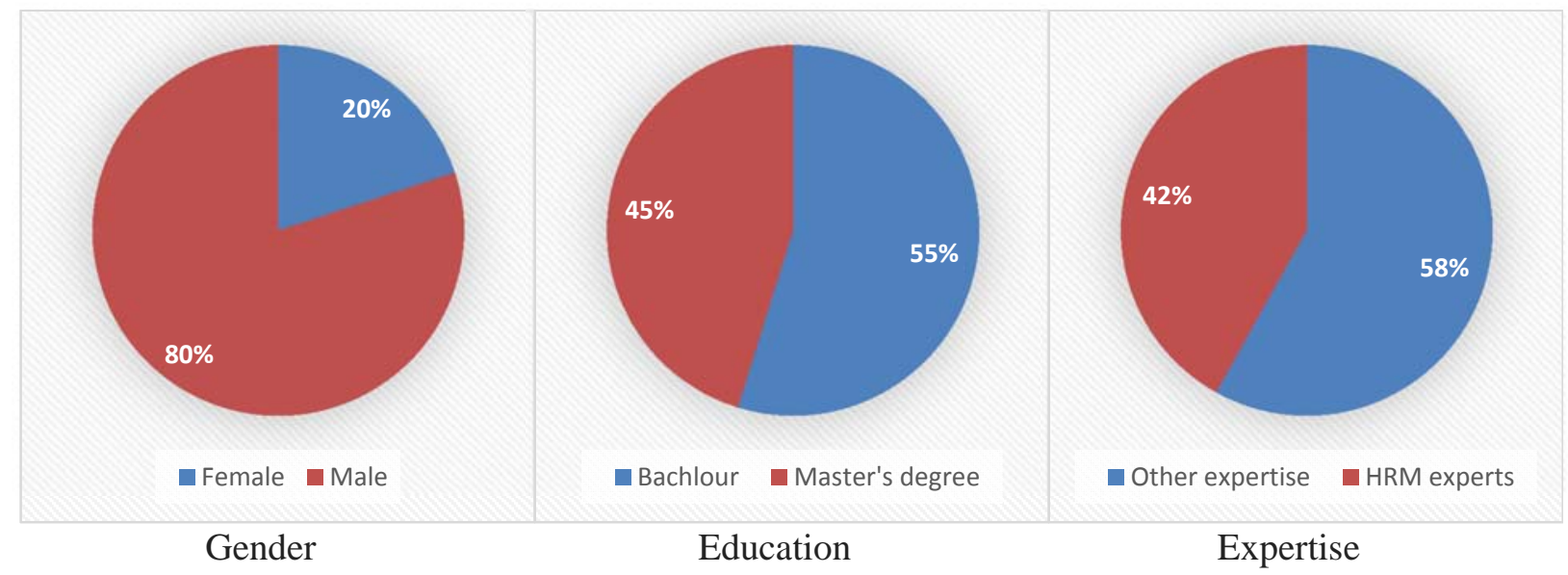

Fig. 1. Personal characteristics of the participants

As we can observe from the results of Fig. 1, 80.06 percent of the respondents were male, 58.1\% had experience more than 15 years, $32.3 \%$ had experience between five to ten years in the human resources department, 38.7 percent were more than 45 years old, 45.2 percent had a master's degree and $41.9 \%$, were the position of Human Resources experts. Table 1 shows the results of the Friedman test for all factors.

Table 1

Results of Friedman test for all factors

\begin{tabular}{cccc}
\hline Variable & Average Rating & Variable & Average Rating \\
\hline $\begin{array}{c}\text { The lack of a comprehensive plan to implement } \\
\text { green human resources management }\end{array}$ & 9.27 & Lack of knowledge & 7.65 \\
$\begin{array}{c}\text { Lack of green human resources management } \\
\text { infrastructures }\end{array}$ & 8.31 & Ambiguous of green value & 8.63 \\
$\begin{array}{c}\text { Lack of culture } \\
\text { The Lack of understanding of green policies }\end{array}$ & 7.89 & Staff resistance & 7.35 \\
The unavailability of HR system structure & 7.63 & Implementation expenses & 3.58 \\
Lack of organizational leadership support & 7.55 & Managers resistance & 7.13 \\
$\quad$ Lack of technical support & 7.08 & & 4.66 \\
\hline $\begin{array}{c}\text { Complexity and difficulty of adoption of green } \\
\text { technology }\end{array}$ & 4.27 & & \\
\hline
\end{tabular}

As can be seen, the lack of a comprehensive plan to implement green human resources management, and Ambiguous of green value have the highest priority. In addition staff resistance was the least 
important factor. Jafri (2012) examined green HR activities in the Indian automobile industry. He concluded that the main barrier to the implementation of green HRM was costs of its implementation. Rompa (2011) also, reached this conclusion. Their findings were inconsistent with findings of this study. In addition, Rompa (2011) stated that lack of knowledge could be considered as a barrier to the implementation of green HRM. Obviously, this is somewhat similar to the findings of this research. On the following, Friedman test based on overall categories are examined. Table 2 shows the results for cultural barriers. The items indicate that, in the first step to implement green HRM, the issue should include in organization's vision, and in the second step, clarification must be accomplished and correct interpretation of green values must be incorporated.

Table 2

Friedman test based on cultural barriers

\begin{tabular}{cc}
\hline Variable & Average Rating \\
\hline Ambiguous of green value & 1.61 \\
Lack of green culture & 1.39 \\
\hline
\end{tabular}

Among the cultural factors, lack of ambiguous of green value has maintained the highest priority. Values has been the most important organizational factor to determine the future direction. Therefore, a correct interpretation of these values must be accomplished. Table 3 demonstrates the results of the Friedman test for technological factors.

Table 3

Results of Friedman test for technological factors

\begin{tabular}{cc} 
Variable & Average Rating \\
\hline Complexity and difficulty of adoption of green technologies & 2.42 \\
Lack of technical support & 2.15 \\
Lack of green human resources management infrastructures & 1.44 \\
\hline
\end{tabular}

Among the technological factors, the complexity and difficulty of the key green technology is the most important factor. We must think of ways to facilitate this. One of these solutions is localization, Sampling of foreign successful organizations, providing information about the tech and is the contexts for the adoption of the technology. Table 4 shows the results of the Friedman test for managerial factors.

Table 4

Results of Friedman test for the managerial factors

\begin{tabular}{cc}
\hline Variable & Average Rating \\
\hline The lack of a comprehensive plan to implement green human resources management & 2.48 \\
Lack of organizational leadership support & 2.1 \\
Managers resistance & 1.42 \\
\hline
\end{tabular}

As we can observe, among management factors, the lack of a comprehensive plan to implement green HRM is the most important factor. It is clear that if there is not a comprehensive plan, there is no commitment to implementation. In addition, the comprehensive plan defines the implementation's guidelines and an operational plan is based on it. However, it should be noted that the lack of a comprehensive plan to implement green HRM creates ambiguity. Table 5 shows the results of the Friedman test for the factors related to staff.

Table 5

Results of Friedman test for employee

\begin{tabular}{cc}
\hline Variable & Average Rating \\
\hline The Lack of understanding of green policies & 2.37 \\
Lack of knowledge & 2.32 \\
Staff resistance & 1.31 \\
\hline
\end{tabular}


Lack of understanding of politics, policy from employees as the most important barrier in staff factors. It highlights the importance of strong corporate communications system. Because, if appropriate culture is executed correctly and it transfers to the staff, the issue is not barrier for the implementation of green HRM. In addition, correct interpretation of the issue should be exist. Obviously, managers and staff must be aware of the policy and if there is not a clear image for staff about it; they will not accept responsibility for implement it.

\section{Conclusion}

Oil is necessary material for many industries and an important source of energy in the international level and the source of 32\% of energy in Europe and Asia and more than 53\% in Middle East. The highest volume products of the industry are fuel oil and gasoline. Oil is a raw material for many chemical products, including pharmaceuticals, solvents, fertilizers, pesticides, herbicides, etc. Regarding the status of the petrochemical industry in the today's world, we should not ignore the damage to humans and the environment and look for the solutions to reduce these damage (Dobaradaran and Mohammadzadeh, 2014). So, the oil industry must consider all aspects of this approach and implement it. As a result, it can be said that, the approach should be implemented in human resources department. In other word, there is a growing need for the integration of environmental management into Human Resource (HR) (Dutta, 2012). The implementation of green HRM is needed to implement the HR strategic systems that fit the organization's culture and long-term objectives (Sudin, 2011). This item is similar to the research conclusion and the researchers believe that green management system can only be effectively implemented if the companies have the right people with the right skills and competencies (Sudin, 2011). The improvement in green innovation depends on the availability and capability of human resources (Sudin, 2011). Rangarajan and Rahm (2011) concluded that income, education, environmental awareness and previous experience in the field of green issues have positive effects in implementation of green HRM. Also, changes in operating procedures and employee behavior is critical in order to implementation green management.

The results of the study have revealed that the most important barriers to the implementation of green HRM were the lack of a comprehensive plan to implement green HRM, and ambiguous of green value. Also, staff resistance has maintained the lowest importance. Peng and Lin (2008) considered staff pressure and resistance as a main factor to implement green HRM and there are not consistent with the results of this study. Looking carefully and according to categories, among the cultural factors, ambiguous of green value among the technological factors, the complexity and difficulty of acceptance of green technology, among management factors, the lack of a comprehensive plan to implement green human resources management, and among the factors related to staff, the lack of understanding of green policies, have had the highest priorities. Jackson and Seo (2010) concluded that lack of interest and complexity were barriers of green HRM, which are consistent with the results of this investigation. According to them, many factors such as lack of knowledge, Uncertainty, distrust the source of information, resistance to change and fatalism can lead to lack of interest.

Also, according to their view, in addition to the complexity and difficulty of acceptance of green technology, there are other barriers for the implementation of green HRM. For instance, designing and evaluating effective green HRM requires an understanding of the green consequences associated with an organization's operations, supply chain, distribution processes, customer behaviors, product life cycles, etc. In addition, Rompa (2011), considered the lack of technological support as a barrier to the implementation of green HRM, where the lack of support, may be due to the complexity of technology acceptance. In other word, the researcher expressed lack of stakeholder support as another barrier to the implementation of green HRM.

According to the results of the paper, suggestions can be offered for oil industry and future researchers. For example, we may consider a comprehensive plan to implement green HRM by the oil industry, incorporate these concept in the organizational vision, articulate and institutionalize of the green values, 
creating green committee in the oil industry, creating international thinking in the industry, sampling of foreign successful organizations and gain support managers. Paille et al. (2013) identified lack of support from managers as the major barrier to green HRM. Harvey et al. (2012) concluded that HRM play crucial role in implementing green practices. However, they faced considerable challenges. Rompa (2011) also believed that organizational leaders must facilitate the green activities and involve staff in Green performance.

Considering the barriers to green HRM in the petrochemical industry, automotive and hospitals, presenting a model for indigenous green human resources management in the oil industry or other industries, examining the relationship between green HRM and productivity index are other suggestions for future researchers.

Limitations of above study includes lack of cooperation and limitation of time experts and unfamiliarity among experts about the issue, lack of green culture, and internal literature in the field.

\section{Acknowledgement}

The authors would like to thank the anonymous for constructive comments on earlier version of this paper. We are also delighted for the cooperation of Iranian oil industry experts in accomplishment of this survey.

\section{References}

Borrego, M., Douglas, P.E., \& Amelink, T. C. (2009). Quantitative, qualitative, and mixed research methods in engineering education. Journal of Engineering Education, 98(1), 53-66.

Chen, S.Y., Tien, P.W., Chen, K.C., \& Lee, I.U. (2012). The influence of environmental commitments on green intellectual capital. Business and Information, 283-308.

Correa, A. A. J., Tapia, M. I., \& Torres, H. E. N. (2013). Proactive Environmental Strategies and Employee Inclusion: The Positive Effects of Information Sharing and Promoting Collaboration and the Influence of Uncertainty. Organization \& Environment, 26, (2), 139-161.

Daily, F. B., \& Huang, C. S. (2001). Achieving sustainability through attention to human resource factors in environmental management. International Journal of operations \& production management, 21(12), 1539-1552.

Delmas, M. A., \& Pekovic, S. (2013). Environmental standards and labor productivity: Understanding the mechanisms that sustain sustainability. Journal of Organizational Behavior, 34(2), 230-252.

Dobaradaran, S., \& Mohamadzadeh, F. (2014). Servey of the oil and gas pollutant impacts on the human and environment. Iranian South Medical Journal, 17, (1), 85-98.

Dutta. S. (2012). Greening people: a strategic dimension. ZENITH International Journal of Business Economics \& Management Research, 2(2), 143-148.

Harvey, G., Williams, K., \& Probert, J. (2012). Greening the airline pilot: HRM and the green performance of airlines in the UK. The International Journal of Human Resource Management, 23, $1-15$.

Hussain, M. (2013). Human resources practices related to environmental Sustainabilit. Master thesis. Polo TERRITORIALE di Como.

Jabbour, C. J. C. (2011). How green are HRM practices, organizational culture, learning and teamwork? A Brazilian study. Industrial and Commercial Training, 43(2), 98-105.

Jabbour, C. C. (2013). Environmental training in organisations: From a literature review to a framework for future research. Resources, Conservation and Recycling, 74, 144- 155.

Jabbour, C. J. C., \& Santos, A. C. F. (2008). Relationships between human resource dimensions and environmental management in companies: proposal of a model. Journal of Cleaner Production, 16, 51-58.

Jackson, E. S., \& Seo, J. (2010). The greening of strategic HRM scholarship. Organization Management Journal, 7, 278-290. 
Jafri, S. (2012). Green HR practices: an empirical study of certain automobile organizations of India. Human Resource Management, 42, 6193-6198.

Johnson, B. R., Onwuegbuzie, J. A., \& Turner, A. L. (2007). Toward a definition of mixed methods research. Journal of Mixed Methods Research, 1(2), 112-133.

Kaur, H. (2013). Today's Success Mantra-Going Green at Functional Areas of HRM. International Journal of Management \& Business Studies, 3(1), 96-99.

Lee, H. K. (2009). Why and how to adopt green management into business organizations?: The case study of Korean SMEs in manufacturing industry. Management Decision, 47(7), 1101-1121.

Mandip, G. (2012). Green HRM: People management commitment to environmental sustainability. Research Journal of Recent Sciences, 1, 244-252.

Margaretha, M., \& Saragih, S. (2013). Developing new corporate culture through green human resource practice. International Conference on Business, Economics, and Accounting, 1-10.

Olusanya, K. L. (2013). Embedding environmental sustainability competencies in human capital training and development. Mediterranean Journal of Social Sciences, 4(4), 65-71.

Paille, P., Chen, Y., Boiral, O., \& Jin, J. (2013). The impact of human resource management on environmental performance: An employee-level study. Journal of Business Ethics, 10, 1-16.

Peng, S. Y., \& Lin, S. S. (2008). Local responsiveness pressure, subsidiary resources, green management adoption and subsidiary's performance: Evidence from Taiwanese manufactures. Journal of Business Ethics, 79(1), 199-212.

Ramus, A. C. (2002). Encouraging innovative environmental actions: what companies and managers must do. Journal of world business, 36, 151-164.

Rangarajan, M., \& Rahm, D. (2011). Greening human resources: A survey of city-level initiatives. Review of Public Personnel Administration, 31(3), 227-247.

Rompa, I. (2011). Explorative research on Sustainable Human Resource Management. Master's Thesis. University of Amsterdam.

Renwick, D., Redman, T., \& Maguire, S. (2008). Green HRM: A review, process model, and research agenda. University of Sheffield Management School.

Renwick, S. W. D., Redman, T., \& Maguire, S. (2013). Green human resource management: A review and research agenda. International Journal of Management Reviews, 15, 1-14.

Rompa, I. (2011). Explorative research on Sustainable Human Resource Management. Master's Thesis. University of Amsterdam.

Sudin, S. (2011). Strategic Green HRM: A proposed model that supports corporate environmental citizenship. International Conference on Sociality and Economics Development, IPEDR, 10, 7983.

Teixeira, A. D., Jabbour, C. J. C., \& Jabbour, S. L. B. (2012). Relationship between green management and environmental training in companies located in Brazil: A theoretical framework and case studies. International Journal of Production Economics, 139(2), 1-12.

Sathyapriya, J., Kanimozhi, R., \& Adhilakshmi, V. (2013). Green HRM- delivering high PERFORMANCE HR systems. International Journal of Marketing and Human Resource Management, 4, (2), 19-25. 